Emir. J. Food Agric. 2015. 27 (1): 82-93

doi: 10.9755/ejfa.v27i1.17884

http://www.ejfa.info/

Drought and Temperature Stress

REGULAR ARTICLE

\title{
Regulatory mechanism of enhancing polyphenol oxidase activity in leaf of Basella alba induced by high temperature stress
}

\author{
M. R. Siddika ${ }^{1}$, M. A. Rakib ${ }^{1}$, M. Abu Zubair ${ }^{2}$, M. M. Islam ${ }^{1}$, M. S. Haque ${ }^{* 1}$ and J. M. Al-Khayri ${ }^{3}$ \\ ${ }^{I}$ Department of Biochemistry and Molecular Biology, Laboratory of Protein and Enzyme Research, University of \\ Rajshahi, Rajshahi 6205, Bangladesh \\ ${ }^{2}$ Department of Food Technology and Nutritional Science, Mawlana Bhashani Science and Technology University, \\ Tangail 1902, Bangladesh \\ ${ }^{3}$ Department of Agricultural Biotechnology; College of Agriculture and Food Sciences, King Faisal University, Al- \\ Hassa 31982, Saudi Arabia
}

\begin{abstract}
High temperature is recognized to be a major abiotic stress involved in diverse metabolic regulation in plants. However, the regulatory mechanism of high temperature induced polyphenol oxidase (PPO) activity in Basella alba is not clarified. B. alba plants grown in pots were exposed to $45^{\circ} \mathrm{C}$ for 24,48 and $72 \mathrm{~h}$ periods and the control plants were kept at $30^{\circ} \mathrm{C}$. The PPO activity in leaves of plants was up regulated and the effects were more pronounced at $24 \mathrm{~h}$ of treatment. To clarify the regulatory mechanism of enhancing the effect, plants were treated with $10 \mathrm{mM} \mathrm{Na} 2 \mathrm{HAsO}_{4}$ and exposed to $45^{\circ} \mathrm{C}$ for the above mentioned periods. $\mathrm{Na}_{2} \mathrm{HAsO} 4$ along with high temperature causes similar stimulatory effects of PPO activity when compared to respective control. Therefore, both high temperature and arsenic treatment may cause additive stresses and enhance the PPO activity. To further clarify the mechanism of high temperature induced PPO activity, plants were treated with 1 $\mathrm{mM}$ Nifedipine, a recognized calcium channel blocker and exposed to $45^{\circ} \mathrm{C}$. Treatment with blocker effectively prevented the activity induced by high temperature almost to the control level which shows clearly that high temperature-induced activity is mediated through calcium channel and may affect cellular concentration of calcium. The results suggests that increased PPO activity might be due to oxidative stress and that arsenic and calcium play a critical role in this phenomenon, thereby the plants survive in adverse environment.
\end{abstract}

Key words: Arsenic, Adaptive response, Basella alba, Metabolic effects, Temperature stress

\section{Introduction}

Diverse environmental stresses differentially affect plant processes that lead to loss of cellular homeostasis accompanied by the formation of reactive oxygen species (ROS), which causes oxidative damage to membrane, lipids, proteins and nucleic acids (Srivalli et al., 2003). To prevent the oxidative damage caused by such abiotic stress, plants generate the different mechanism by which they survive in such critical environment. Anti oxidative enzymes and antioxidant molecules like

Received 13 February 2014; Revised 15 April 2014; Accepted 25 April 2014; Published Online 15 December 2014

*Corresponding Author

M. S. Haque

Department of Biochemistry and Molecular Biology, Rajshahi University, Rajshahi 6205, Bangladesh

Email: haque_drshahidul@yahoo.co.in superoxide dismutase, catalase and polyphenol oxidase are the most important components in the scavenging system of ROS and have been found to be involved in neutralizing ROS (Oidaira et al., 2000; Lee and Lee, 2000). It has been revealed that draught and high temperature stresses adversely affect growth and productivity of plants thereby causing the impairment of yield and yield characters (Zlatev and Lidon, 2012). Therefore, it is well recognized that high temperature is critically involved in diverse metabolic regulation and the oxidative stress caused by high temperature therefore, is involved in inducing the synthesis of ROS which damages and injury to the plants. However, plants adapt to this adverse situation by synthesis of some enzymes which may play the critical role in metabolic regulation and coordination in the biosphere.

The enzymatic destruction of phenolics is typically an oxidative process with molecular 
oxygen $\left(\mathrm{O}_{2}\right)$ serving as the oxidant for oxidases and hydrogen peroxide $\left(\mathrm{H}_{2} \mathrm{O}_{2}\right)$ as the oxidant for peroxidases (Mayer, 2006). Phenolic oxidases and peroxidases are ubiquitous in vascular plants, mosses and fungi. In plants, the enzymes are typically concentrated in shoot tissues that contain plastids (chiefly chloroplasts) fruits and seeds (Mayer, 2006) but have also been found in either aerial roots of orchids or belowground tubers. Polyphenol oxidase (PPO) has been widely recognized to be involved in causing the biosynthesis of diverse metabolites essential for diagnosis and other purposes (Velero et al., 2003) and has been found to be linked in scavenging system of reactive oxygen species synthesized in the biological system. Polyphenol oxidases are enzymes with molecular weight of 60 $\mathrm{kDa}$ located in the chloroplast bound to thylakoid membranes, belonging to a group of copper containing metalloproteins and are members of oxido-reductases that catalyze the oxidation of a wide range of phenolic compounds by utilizing molecular oxygen (Queiroz et al., 2008). In presence of atmospheric oxygen and PPO, monophenol is hydroylated to o-diphenol and diphenol can be oxidized to o-quinones which then undergo polymerization to yield dark brown polymers.

High temperature is a well recognized environmental abiotic stress and stimulus causing diverse metabolic alteration in plants. Severe stress causes alteration of membranes organization, enzyme inactivation and other metabolic imbalance. However, the plants survive in this adverse environment by different mechanical and altered biological processes. Upregulation of many genes has been observed to help the plant to withstand the stress conditions which lead to plant adaptation. Upon stress plants perceive the external and internal signals through different independent or interlinked pathways which are used to regulate various responses for its tolerance development (Figure 2). Plants must be protected from heat-induced oxidative stress so that they can survive under high temperature. Tolerance to high temperature stress in crop plants has been associated with an increase in antioxidative capacity (Almeselmani et al., 2006; Babu et al., 2008). Tolerant plants entail a tendency of protection against the damaging effects of ROS with the synthesis of various enzymatic and nonenzymatic ROS scavenging and detoxification systems (Apel and Hirt, 2004). During drought or high temperature in the environment, polyphenol oxidase might be involved in prevention of oxidative damage in plant and therefore could be an essential index for the adaptive mechanism in adverse circumstances.
Arsenic has been identified to be toxic to the living organisms. Bioavailability, uptake and phytotoxicity of arsenic to plants are influenced by factors such as arsenic concentration in soil, arsenic species, plant species and soil properties (Mascher et al., 2002). Under environmental stresses, plants often produce reactive oxygen species (ROS) such as superoxide, hydrogen peroxide and hydroxyl radicals, causing damage to DNA, proteins and lipids. There is significant evidence that arsenic exposure leads to the generation of ROS through the conversion of arsenate to arsenite, a process that readily occurs in plants (Mascher et al., 2002). To minimize the harmful effects of ROS, plants have evolved an effective scavenging system composed of antioxidant molecules and antioxidant enzymes (Singh et al., 2006). The oxidation of phenolic compounds and their metabolism in response to high temperature might be affected by arsenic. Recent study reveals that increased oxidative stress caused by high temperature is mediated with cellular concentration of $\mathrm{Ca}+2$ (Larkindale and Knight, 2002). Therefore, it is assumed that high temperature stress may affect calcium channel for entry of calcium in this species of plant.

Basella alba (Pui) is a very soft leafy common vegetable available in Bangladesh and grows both in summer and winter and therefore, both seasons were believed to be involved in regulating metabolic alterations in this species of vegetable. The diverse clinical importance of this plant was demonstrated by recent investigations (Roshan et al., 2012; Premalatha et al., 2005). In response to high temperature, these species of plant have been found to survive in the atmosphere although the physiological mechanism of survival is not clarified. It has been revealed that temperature variation is a common environmental phenomenon causing diverse metabolic alterations in plants and other organisms (Janska et al., 2010). Changes in environmental temperature affect the plant kingdom either by suppression of their total growth and development or by augmenting diverse physiological, metabolic and superficial changes. Moreover, high temperature has been recognized to be involved in metabolic regulation and has been shown to cause the synthesis of ROS in plants (Mahajan and Tuteja, 2005). Therefore, it is assumed that variation of temperature may affect both metabolic activities as well as its biological importance of this species of plant. The aim of this study is to examine the interrelationship between anti oxidative status and preventive mechanism against temperature stress causing cell injury and physiological alterations in this vegetable which 
involves the enzyme PPO might be involved in playing the critical role in this respect. Therefore, the current investigation has been undertaken to find the role of high temperature exposure on the regulation of metabolic functions regarding the alteration and synthesis of PPO in leaf of B. alba and may assist in the clarification of such stress induced mechanisms.

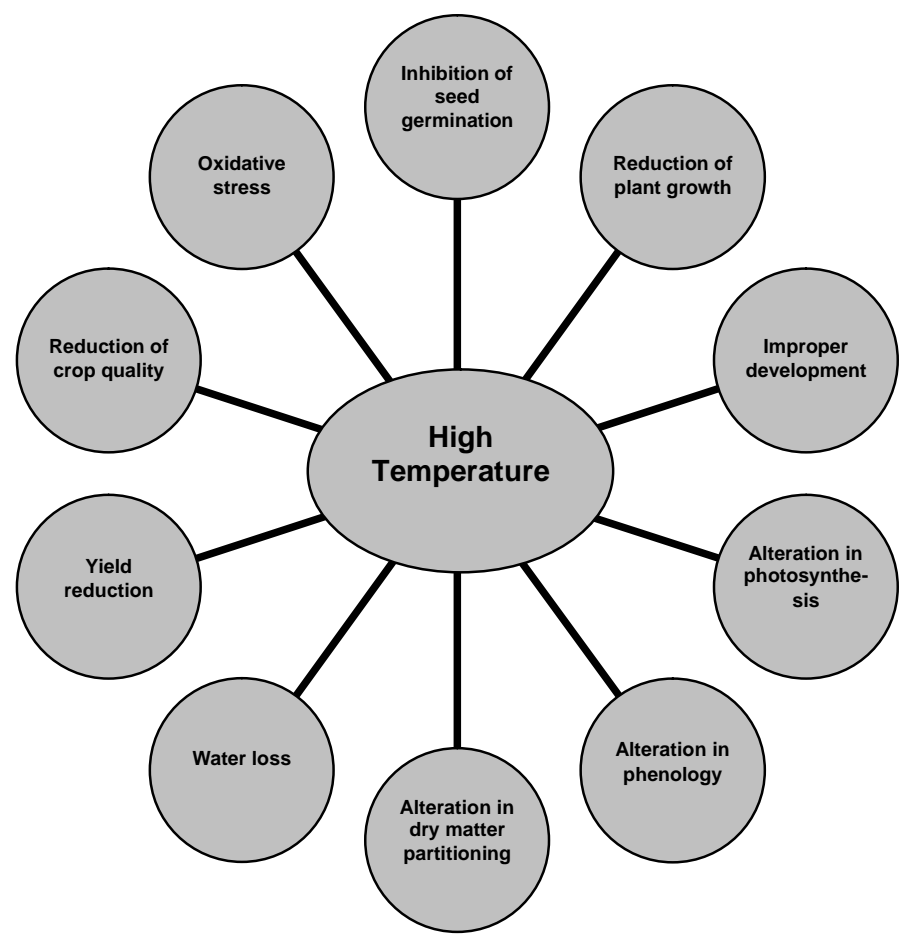

Figure 1. Major effects of high temperature on plants.

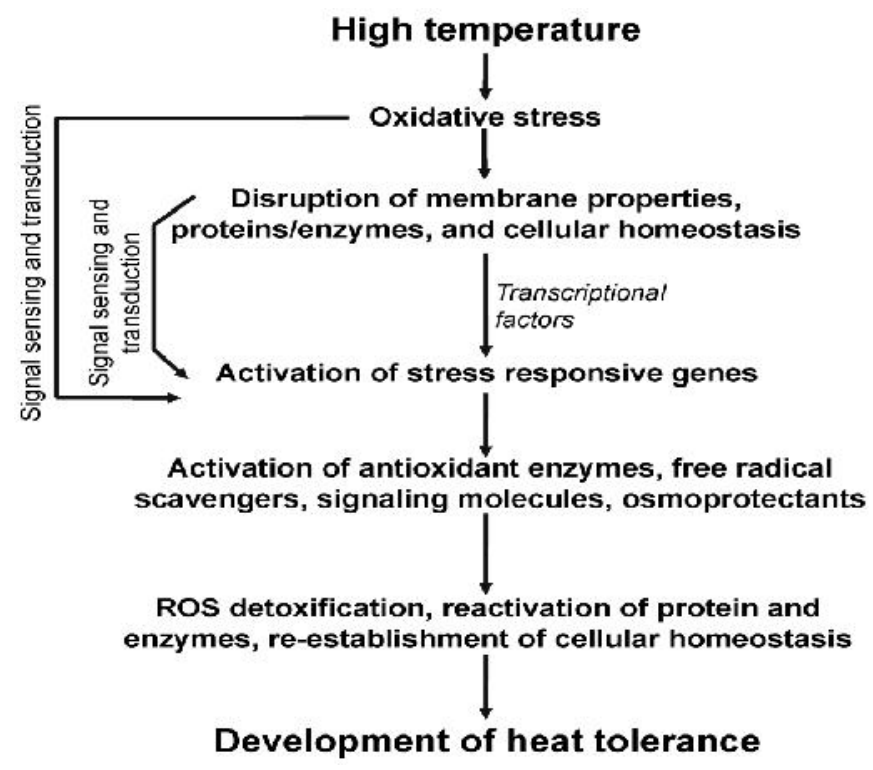

Figure 2. Schematic illustration of heat induced signal transduction mechanism and development of heat tolerance in plants. 


\section{Materials and Methods \\ Plant materials and high temperature treatment}

For this experiment, six plastic pots were used; each pot size was $70 \mathrm{~cm}$ in diameter and $24 \mathrm{~cm}$ in height. An adequate amount of soil was taken in each plastic pot and the plastic pots were seeded with Basella alba. For the germination of seeds, the following points were carried out: i) healthy seeds were selected; the seeds were added to normal water and the floating seeds were discarded; ii) seeds were kept in normal water with temperature $27 \pm 1^{\circ} \mathrm{C}$ for overnight; iii) swollen seeds were expected to be ideal for germination; iv) seeds were sown in the pots prepared with soil. The plants were grown outside of the laboratory in ambient temperature $\left(32 \pm 1^{\circ} \mathrm{C}\right)$ with sufficient sunlight and water. No fertilizer was administered to the soil. After 30 days of germination, plants (approximately $20 \mathrm{~cm}$ height from the ground level) were used for the experiment. After 30 days of germination, pots were considered as control and high temperature induced plants. Control pot was used for 24, 48 and $72 \mathrm{~h}$ treatments at room temperature; however, the temperature was maintained $30^{\circ} \mathrm{C}$ by using air cooling system (AC). The high temperatureinduced pot was used similarly for 24,48 and $72 \mathrm{~h}$ duration in the plastic chamber and was exposed to $45^{\circ} \mathrm{C}$ with full aeration along with sufficient water. To maintain this temperature, electric bulbs $(2 \times 200$ W) were connected to the chamber. After the treatments, the leaves were collected consecutively from each pot for 24, 48 and $72 \mathrm{~h}$ duration and stored at $-80^{\circ} \mathrm{C}$.

\section{$\mathrm{Na}_{2} \mathrm{HAsO}_{4}$ and Nifedipine treatment}

Plants were treated with $10 \mathrm{mM} \mathrm{Na} \mathrm{HAsO}_{4}$ ( $800 \mathrm{ml}$ was poured and dispersed to the soil of each pot) and exposed to $45^{\circ} \mathrm{C}$ for 24,48 and $72 \mathrm{~h}$ periods and the respective controls were treated with $10 \mathrm{mM} \mathrm{Na} 2 \mathrm{HAsO} 4(800 \mathrm{ml})$ only. After the treatment, leaves were collected consecutively from the high temperature induced plants and controls. Similarly, plants were treated with $1 \mathrm{mM}$ Nifedipine, a recognized calcium channel blocker (Square Pharmaceuticals Ltd., Bangladesh) (500 $\mathrm{ml}$ ) (Nifedipine was dissolved in $100 \mathrm{ml}$ concentrated DMSO solution and made up to 500 $\mathrm{ml}$ with distilled water) and induced by high temperature $\left(45^{\circ} \mathrm{C}\right)$ for the above mentioned periods however the respective controls were treated with $1 \mathrm{mM}$ blocker $(500 \mathrm{ml})$ only and exposed to $30^{\circ} \mathrm{C}$. It is important to note that all the above solutions were carefully poured and dispersed to the soil of the respective pots rather than the upper parts of plants. After the treatments, leaves were similarly collected from the pots consecutively for the respective periods and kept in $-80^{\circ} \mathrm{C}$. Leaves collected from the above treatments were used for the assay of polyphenol oxidase activity according to the conventional procedure as described below.

\section{Assay of polyphenol oxidase (PPO) activity}

The leaves of the different treatments $(24,48$ and $72 \mathrm{~h}$ ) and their respective controls were homogenized with $22 \mathrm{ml}$ distilled water in a mortar kept on ice. Approximately, $1.5 \mathrm{~g}$ of high temperature-induced and their respective control leaves were used for homogenization. The homogenates were centrifuged at $9000 \mathrm{rpm}$ for 15 min and the supernatants were used as crude extract for assay of PPO activity spectrophotometrically as described by Mahadevan and Sridhar (1982) based on an initial rate of increase in absorbance at 495 $\mathrm{nm}$ where, catechol was used as substrate. One unit of enzyme activity is defined as a change in absorbance of $0.001 \mathrm{~min}^{-1} \mathrm{ml}^{-1}$ of enzyme extract. For determination of PPO activity in leaf, $3 \mathrm{ml}$ of $0.1 \mathrm{M}$ phosphate buffer ( $\mathrm{pH} \mathrm{6.0)}$ ) and $2 \mathrm{ml}$ of crude enzyme extract were taken in the test tube and kept on ice. The contents were mixed, placed in a spectrophotometer using a cuvette and the absorbance was adjusted to zero at $495 \mathrm{~nm}$. The cuvette was removed, $1 \mathrm{ml}$ of catechol $(100 \mathrm{mM})$ was added, quickly mixed by inversion and the changes in absorbance at $495 \mathrm{~nm}$ were recorded for up to $3 \mathrm{~min}(1,2,3 \mathrm{~min})$. In all experiments, three replicates were performed for each sample. The following calculation was used to assay PPO activity in a sample: change in A495 = Af - Ai, where, $\mathrm{Ai}=$ initial absorbance reading and $\mathrm{Af}=$ final absorbance reading. Change in A495 for each sample was used to calculate the units of PPO activity and the activity is expressed as Unit $\mathrm{g}^{-1}$ of leaf weight.

\section{Statistical analysis}

Each extract from the controls as well as treated plants were taken in three tubes and the PPO activity was assayed from these tubes and calculated. Results of the experiments were expressed as mean and standard error of different groups based on three independent determinations. The reported data represent the mean of three replications $(n=3)$. The differences between the mean values were evaluated by ANOVA followed by paired t-test using SPSS software for comparison of changes at $\mathrm{p}=0.05$ level of significance $(\mathrm{p}<0.05)$. 


\section{Results \\ Effect of high temperature stress on PPO activity in leaf}

To properly identify physiological responses to environmental stress such as high temperature, plants were exposed to $45^{\circ} \mathrm{C}$ in the chamber for 24 , 48 and $72 \mathrm{~h}$ periods and the respective controls were kept in ambient room temperature $\left(30^{\circ} \mathrm{C}\right)$. Polyphenol oxidase activities in leaf exposed to high temperature for the above mentioned periods were examined at $100 \mathrm{mM}$ catechol, substrate for the enzyme. As shown in Figure 3, the average PPO activity in leaf of vegetable in response to high temperature for $24 \mathrm{~h}$ period was $11919.11 \pm 508.64$ Unit $\mathrm{g}^{-1}$ of leaf whereas for control leaf kept in ambient temperature, the PPO activity was recorded as $6583.11 \pm 108.17$ Unit. A significant $81.05 \%$ ( $\mathrm{p}<$ 0.01 ) increased PPO activity was observed after 24 $\mathrm{h}$ when compared to the control plant (Figure 4). The results appeared to indicate that the PPO activities were affected by high temperature acclimation. Therefore, it is reasonable that an adaptive response by the species of plant was created and the higher synthesis of PPO was observed to survive in adverse situation and might be sensitive to the temperature variation. Leaves of B. alba were exposed to high temperature for $48 \mathrm{~h}$ period and the average PPO activity was 13697.78 \pm 408.90 Unit while for the respective control plant, the enzyme activity was recorded as $11244.44 \pm$ 540.92 Unit $^{-1}$ of leaf. To find the optimum effect of high temperature exposure on PPO level in leaf, the extended time was $72 \mathrm{~h}$. As shown in Figure 3, the high temperature induced leaf had PPO level $15251.56 \pm 20.43$ Unit while for the respective control leaf, the average PPO level was $14168.00 \pm$

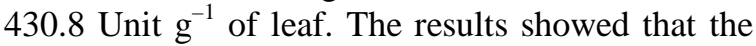
PPO level in leaf had been enhanced (7.64\%) when the plants were exposed to high temperature for 72 $\mathrm{h}$ when compared to control (Figure 4). Moreover, the PPO levels were also affected by high temperature acclimation for prolonged exposure, and seem to be lower than $24 \mathrm{~h}$ or $48 \mathrm{~h}$ period, therefore reasonably assumed to be maximally enhanced after $24 \mathrm{~h}$ of high temperature exposure. Of course, further extension of time may clarify the mechanism of enhancing the synthesis of PPO in response to high temperature.

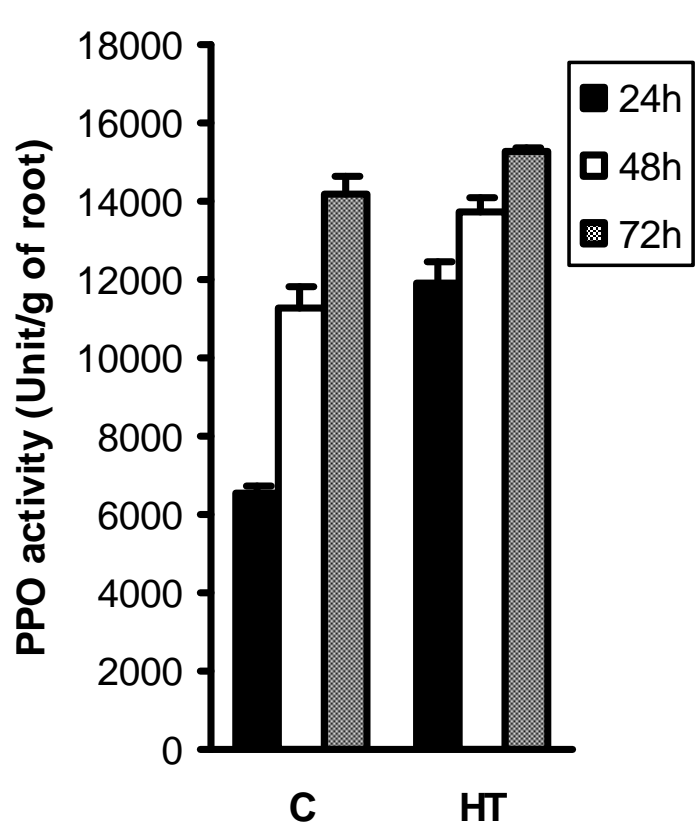

Figure 3. Alteration of PPO activity in leaves of $B$. alba during high temperature (HT) acclimation for 24, 48 and $72 \mathrm{~h}$ as compared to the control (C).

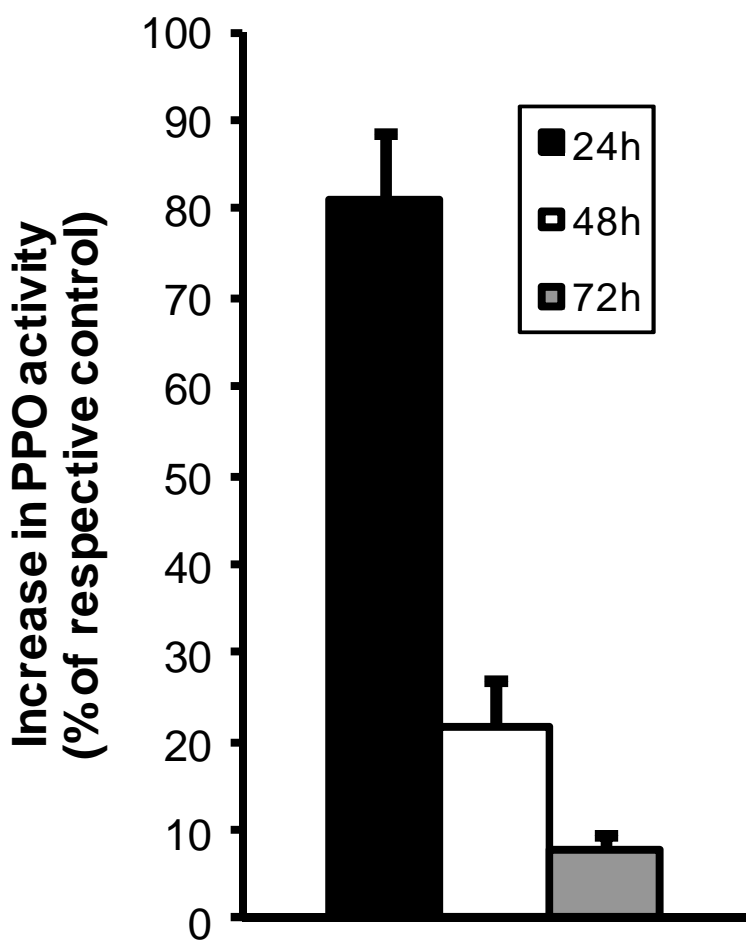

Figure 4. The PPO activity in leaves of $B$. alba exposed to $45 \mathrm{oC}$ for 24,48 and $72 \mathrm{~h}$; however, the respective controls were used without any high temperature exposure. The results are expressed as percentage of the respective controls. 
Table 1. Effect of arsenic on the regulation of PPO activity in leaf of $B$. alba induced by high temperature. The plants were treated with $10 \mathrm{mM} \mathrm{Na}_{2} \mathrm{HAsO}_{4}$ and exposed to $45^{\circ} \mathrm{C}$ for 24,48 and $72 \mathrm{~h}$; however, the respective control was treated with similar concentration of $\mathrm{Na}_{2} \mathrm{HAsO}_{4}$ only. Control plants were similarly used except giving high temperature exposure.

\begin{tabular}{llll}
\hline & \multicolumn{2}{l}{ Polyphenol oxidase (PPO) activity $\left(\right.$ unit g$^{-1}$ of leaf) } \\
\cline { 2 - 4 } Treatments & 24 h exposure & $48 \mathrm{~h}$ exposure & 72 h exposure \\
\hline Control & $6583.11 \pm 108.17$ & $11244.44 \pm 540.92$ & $14168.00 \pm 430.80$ \\
High temperature & $11919.11 \pm 508.64^{\mathrm{A}}$ & $13697.78 \pm 408.90^{\mathrm{D}}$ & $15251.56 \pm 20.43$ \\
Arsenic & $11264.88 \pm 422.46$ & $12266.66 \pm 354.10$ & $14515.55 \pm 408.88$ \\
Arsenic + high & $13104.88 \pm 584.27^{\mathrm{B}, \mathrm{C}}$ & $14720.00 \pm 354.01^{\mathrm{E}, \mathrm{F}}$ & $16764.44 \pm 408.83^{\mathrm{G}, \mathrm{H}}$ \\
temperature & & & \\
\hline
\end{tabular}

The results are means of $\pm \mathrm{SE}$ for three values in each group. $\mathrm{A} \mathrm{p}<0.01, \mathrm{~B} p<0.05$ versus respective control. $\mathrm{C} p<$ 0.01 versus control. $\mathrm{D} p<0.05$, E $\mathrm{p}<0.001$ versus respective control. $\mathrm{F} \mathrm{p}<0.01$ versus control. $\mathrm{G} \mathrm{p}<0.05$ versus respective control. $\mathrm{H} \mathrm{p}<0.05$ versus control.

\section{Effect of $\mathrm{Na}_{2} \mathrm{HAsO}_{4}$ on PPO activity in leaf induced by high temperature}

Arsenic is a potent toxic molecule involved in impairment of biological reactions and causes also oxidative stress. Therefore, to find the role of arsenic on PPO activity, the effects of $\mathrm{Na}_{2} \mathrm{HAsO}_{4}$ on high temperature induced PPO activity were examined. To examine the role of arsenic on high temperature induced PPO activity in leaf of $B$. alba, plants were exposed to high temperature $\left(45^{\circ} \mathrm{C}\right)$ for $24 \mathrm{~h}$ period along with $10 \mathrm{mM} \mathrm{Na} 2 \mathrm{HAsO}_{4}$ and the respective control was treated with similar concentration of arsenic only. The enzyme activity in leaf in response to high temperature was $13104.88 \pm 584.27$ Unit, while for the respective control plant treated with arsenic only for the above mentioned time, the activity was recorded as $11264.88 \pm 422.46$ Unit $^{-1}$ of leaf (Table 1). After $24 \mathrm{~h}$ of treatment, the leaf enzyme level was calculated as $6583.11 \pm 108.17$ Unit for control and for high temperature induced plant only, the value

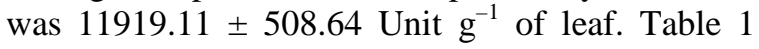
also shows that high temperature causes a significant $(\mathrm{p}<0.01)$ increase $(81.05 \%)$ in PPO level when compared with respective control. The increase in PPO activity determines the higher anti oxidative status for the prevention of high temperature induced physiological stress of the plant. It is important to note that higher the oxidative stress, higher the synthesis of the enzyme thereby the plants survive in the adverse environment.

In response to high temperature for $48 \mathrm{~h}$, the PPO activity in leaf was $13697.78 \pm 408.90$ Unit while the respective control leaf had $11244.44 \pm$ 540.92 Unit $^{-1}$ enzyme activity for the above mentioned time. Table 1 shows the effects of arsenic on high temperature induced PPO activity in leaf of this species where the PPO activity in response to high temperature along with arsenic was $14720.00 \pm 354.01$ Unit while the value for the respective control treated with arsenic was recorded as $12266.66 \pm 354.10$ Unit $^{-1}$. The results (shown in Table 1) demonstrated that prolonged exposure of high temperature had been involved in synthesis of enzyme in leaf of this species of plant and the activity was increased by $21.81 \%$ significantly ( $\mathrm{p}<$ 0.05 ) when compared to the respective control and the effects were significantly enhanced by $30.90 \%$ $(\mathrm{p}<0.01)$ induced by arsenic and high temperature compared to the control plants. The activity was also enhanced significantly $(20.00 \%)(\mathrm{p}<0.001)$ when compared to the respective control treated with arsenic only. The results demonstrate that arsenic causes the additive effects on PPO activity and the effects might be due to the higher oxidative stresses caused by arsenic. Oxidative stress also induces the degradation of a variety of biologically important molecules such as amino acids, protein and carbohydrates, with the consequent release of malondialdehyde. Therefore, the increase in PPO activity in response to arsenic in $B$. alba is more precisely an indicator of arsenic-induced oxidative damage of the phenolic substrates to the colored desirable products such as quinoles due to the impairment of cell defense system.

To further clarification of the role of arsenic on PPO activity induced by high temperature, the plants were exposed to arsenic as well as induced by high temperature for the prolonged periods ( 72 h) where the activity in response to high temperature was $15251.56 \pm 20.43$ Unit and for the control plant, the value was $14168 \pm 430.8$ Unit $^{-1}$ for $72 \mathrm{~h}$ periods (Table 1). The PPO activity in plants treated with arsenic and high temperature was $16764.44 \pm 408.83$ Unit while for the respective control induced by arsenic only, the value was $14515.55 \pm 408.88$ Unit. The results 
indicated that the activity was increased by $18.32 \%$ significantly $(\mathrm{p}<0.05)$ in response to high temperature and arsenic compared to the control plants and also by $15.49 \%$ significantly $(\mathrm{p}<0.05)$ when compared to the respective control induced by arsenic only. The increased activity corresponds to the periods of exposure and also to the higher oxidative stress caused by arsenic and the plants survive in the atmosphere during the higher combined stresses.

\section{Effect of calcium channel blocker on PPO activity in leaf induced by high temperature}

To find the physiological mechanism of high temperature induced PPO activity in leaf of $B$. alba, we further determined PPO activity after 24, 48 and $72 \mathrm{~h}$ periods of high temperature exposure along with Nifedipine, a recognized calcium channel blocker. Figure 5 shows the effect of Nifedipine on high temperature induced PPO activity in leaf for $24 \mathrm{~h}$ of treatment. Plants exposed to high temperature along with Nifedipine had PPO level $5495.30 \pm 35.63$ Unit where as for the respective control treated with Nifedipine only, the PPO activity $7640.85 \pm 206.51$ Unit $\mathrm{g}^{-1}$ of leaf was observed. The PPO activities in response to high temperature and for the respective control were

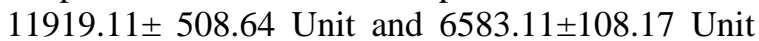
respectively (Figure 3 and 5). The results indicated that the enzyme activity of Basella leaf had been increased by $81.05 \%$ significantly $(p<0.01)$ for high temperature treatment when compared to the respective control while the values were reduced significantly $(\mathrm{p}<0.01)$ by $53.89 \%$ when the plants were treated with calcium channel blocker and high temperature when compared to the plants exposed to high temperature and control. Although some differences between the PPO activities observed in leaf treated with high temperature and blocker and the respective control treated with blocker only were observed however, the differences might be due to the effects of the blocker itself. Oxidative stresses are produced in the cellular level by diverse metabolic pathways caused by environmental or chemical stimuli, however the prevention of these stresses are essential so that the organisms can survive in the environment. The reduced PPO activity in leaf after treatment with Nifedipine is a good indicator for the prevention of oxidative damage. Acclimation to $45^{\circ} \mathrm{C}$ similarly causes the enhanced PPO synthesis in prolonged time $(48 \mathrm{~h})$ and the plants may survive in such critical environment either by synthesis of PPO in their tissues or by other phenomenon. Figure 3 also shows that the PPO level was increased significantly $(\mathrm{p}<0.05)$ by $21.81 \%$ when they were exposed to $45^{\circ} \mathrm{C}$ compared to the respective control where the values were $11244.44 \pm 540.92$ Unit and

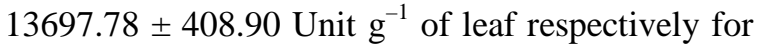
control and high temperature acclimation. Plants were treated with blocker and exposed to high temperature for $48 \mathrm{~h}$ while the respective control plants were treated with blocker only and the PPO activities were $7590.35 \pm 107.66$ Unit and 5483.44 \pm 35.17 Unit for the respective treatments. It was found that treatment with blocker effectively and significantly reduced the PPO activity influenced by high temperature $(44.58 \%)$ ( $\mathrm{p}<0.01)$ when compared to the high temperature induced plants and control (Figure 5). Similar reducing effects were observed whenever the plants were exposed to Nifedipine (calcium channel blocker) and high temperature for $72 \mathrm{~h}$ periods (Figure 5). The activity in response to high temperature along with calcium channel blocker was $7857.43 \pm 61.86$ Unit and for the respective control treated with blocker only was $6029.73 \pm 35.88$ Unit $^{-1}$. On the contrary, plants exposed to high temperature for the above mentioned period had PPO activity $15251.56 \pm$ 20.43 Unit and for the respective control, the value was $14168 \pm 430.8$ Unit $\mathrm{g}^{-1}$ of leaf. Calcium channel blocker in presence of high temperature effectively and significantly $(\mathrm{p}<0.001)$ reduced PPO activity by $48.48 \%$ when compared to the plants exposed to high temperature and control plant while the value was almost similar with the respective control treated with blocker only (Figure 3 and 5). Although $1 \mathrm{mM}$ Nifedipine effectively was involved in reducing the PPO activity in response to high temperature, the variable concentration may produce the optimum effects on the regulation of the enzyme activity. High temperature causes the degradation of the phenolic substrates because of the higher oxidative stresses while the reduced value of PPO in response to Nifedipine might be an index for the prevention of degradation of the substrates. 
(A) $24 \mathrm{~h}$

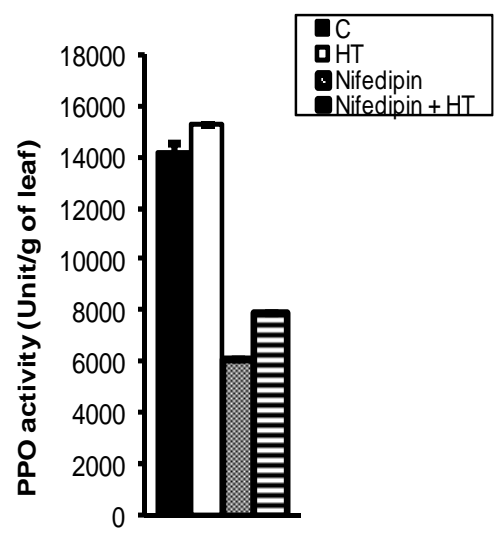

(B) $48 \mathrm{~h}$

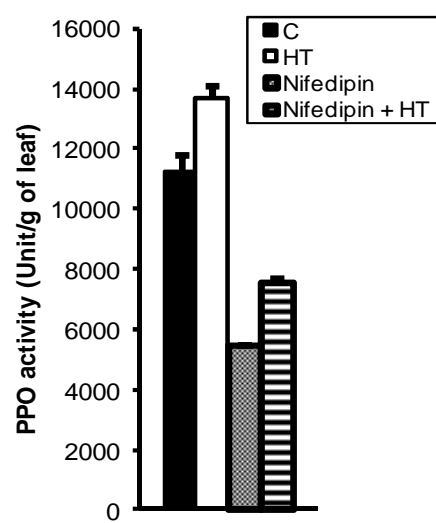

(C) $72 \mathrm{~h}$

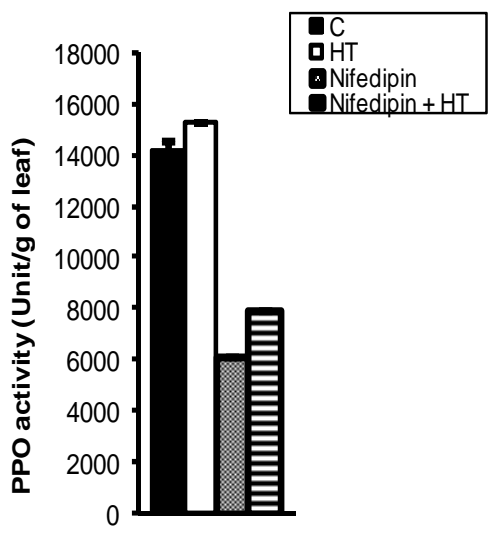

Figure 5. Effects of calcium channel blocker on high temperature induced PPO activity in leaf of $B$. alba. The plants were treated with $1 \mathrm{mM}$ Nifedipine and exposed to high temperature for (a) $24 \mathrm{~h}$, (b) $48 \mathrm{~h}$ and (c) $72 \mathrm{~h}$ and the respective controls was treated with similar concentration of Nifedipine only. The plants were exposed to $45^{\circ} \mathrm{C}$ for $24 \mathrm{~h}(\mathrm{HT}), 48 \mathrm{~h}$

(HT) and $72 \mathrm{~h}(\mathrm{HT})$, however the respective controls (C) were used without any high temperature exposure.

\section{Discussion}

High temperature is known to be a major abiotic stress causing physiological and metabolic alterations in plants. This abiotic stress produces multifarious, and often adverse, alterations in plant growth, development, and reduced yield (Figure 1). However, to identify the mechanism of plant species responses to high temperature particularly the physiological and adaptive responses, assay of polyphenol oxidase activity in leaf of $B$. alba was performed. In this respect, plants were grown in pot and exposed to $45^{\circ} \mathrm{C}$ for 24,48 and $72 \mathrm{~h}$ periods. High temperature was found to be involved in causing higher PPO activity in leaf and the effects were more pronounced after $24 \mathrm{~h}$ of exposure although gradual increase in activity up to $72 \mathrm{~h}$ of periods was noted. It has been demonstrated that high temperature causes the higher oxidative stress inducing the synthesis of reactive oxygen species (ROS) (Mahajan and Tuteja, 2005) and increases tolerance to ROS in plants and with an increase in anti-oxidative enzymes (Scotti-Campos et al., 2014). Anti-oxidative enzymes can neutralize ROS and thereby prevents the cellular membranes and organelles from the damaging effects of ROS. It is reasonable that fluctuation of temperature can cause stress to the normal physiological functions of plants, and hence alteration of metabolic activities in leaf of the plant might be observed. Basella alba is a common green vegetable grown in Bangladesh and other countries during both winter and summer seasons. Therefore, the plants have the higher sensitivity to these temperatures; however, the plants survive in very hot environment although the mechanism is not clarified. Since high temperature causes the significant alteration in metabolic functions of plant and has been revealed to cause reactive oxygen species, therefore might be involved in causing the synthesis of diverse metabolites essential for various purposes. The reactive oxygen species have been shown to cause the injury in plants during the critical circumstance and therefore, to survive in this environment, plants generate different mechanisms and synthesize the compounds. Oxidative stress can arise from an imbalance between the generation and elimination of reactive oxygen species (ROS), leading to excess ROS levels that causes indiscriminate damage to virtually all biomolecules, leading, in turn, to various diseases and cell death (Scandalios, 2005). Reactive species can be eliminated by a number of enzymatic and non-enzymatic antioxidant defense mechanisms (Boullier et al., 2001) therefore, the higher activity of PPO in response to high temperature in species of Pui vegetable might be linked to the defense mechanisms and the results are consistent with their findings. 
Abiotic stress leads to a series of molecular, biochemical, physiological and morphological changes that adversely affect plant growth and productivity. High temperature is a major factor limiting the productivity and geographical distribution of many species, including important agricultural crops. Higher plants manifest a unique capability of the synthesis of a large amount of diverse molecules so-called secondary metabolites, such as phenolic compounds and the synthesis and release of phenolics are induced by various biotic and abiotic factors (Makoi and Ndakidemi, 2007). It has been demonstrated in the previous study that anti oxidative enzyme activities are regulated in response to different types of stress, both biotic and abiotic (Yadegari et al., 2007). More specifically, these enzymes have been related to the appearance of physiological injuries caused by thermal stress. The results indicated that $21.81 \%(\mathrm{p}<0.05)$ increased PPO had been found after $48 \mathrm{~h}$ in response to high temperature compared to the control plant as illustrated in Figure 3 and 4. The increased synthesis of PPO in leaf in response to high temperature might be involved in the regulation of metabolic functions of this species of plant. The alteration of PPO level in leaf is an index for characterization of the sensitivity to the environmental temperature. The results suggest that the increased PPO induced by high temperature might be caused by such abiotic and oxidative stress and could be considered as the survival factor for this species of plant in critical environment. During the experiment, it was observed that both high temperature induced and the respective controls caused the color pigmentation quickly, however high temperature induced leaves had higher pigmentation than the control during the polyphenol oxidase assay therefore, it is reasonable that high temperature acclimation causes the higher oxidation of phenolic compounds and might be an effective approach for the regulation of the synthesis of colored pigment essential for the several purposes. Of course, the phenomenon is a substantial mechanical and physiological way by which the plants survive in the adverse environment. The oxidation of phenolic compounds might be related to the temperature variation in the environment.

The results show that application of arsenic along with high temperature treatment enhance the PPO activity in leaf when compared to the control however the values were higher than the high temperature treated leaf alone. Therefore, additive effects of arsenic in inducing the higher activity of
PPO were demonstrated during the experiment. The results indicated that PPO activity in leaf was increased by arsenic treatment $(99.06 \%)$ significantly $(\mathrm{p}<0.01)$ when compared to control and compared to the respective control treated with arsenic, the value was increased significantly ( $\mathrm{p}<$ 0.05 ) by $16.33 \%$. The increased activity in response to high temperature and arsenic determines the higher conversion of phenolic compounds to the desirable products as this enzyme has higher specificity for the oxidation of phenolic compounds. The higher activity of PPO is an essential parameter for producing the colored pigment substantial for industrial and other purposes. Arsenic has been recognized to be a major toxic element for the growth of plants and is involved in impairment of metabolic and physiological effects in the organisms. It is assumed that arsenic itself may cause the oxidative stress to the plants and enhance PPO activity. Along with high temperature, therefore, reasonably arsenic produces additive PPO activity. The previous study reveals that arsenic accumulation in plant tissues causes several metabolic and physiological disorders (Mumthas et al., 2010), thereby adversely affect growth performance which ultimately leads to reduction of the plant productivity. Arsenic replaces phosphate from ATP to form unstable ADP-arsenic and leads to the disruption of energy metabolism in plant cell. It has been reported that arsenic induces the generation of ROS during its valence change, a process that readily occurs in plants (Mascher et al., 2002). These ROS may lead to peroxidation of lipids which is considered as an indicator of oxidative stress. Plants may minimize the production of ROS or it may protect itself from deleterious effect of ROS by efficiently scavenging of ROS. The scavenging system controlling reactive oxygen species (ROS) comprises non-enzymatic and enzymatic components. Although some reports are available on response of enzymatic antioxidant system in higher plants exposed to arsenic (Mascher et al., 2002; Sri et al., 2009), contradictory reports could not allow to compile the whole mechanism of arsenic mediated oxidative stress and antioxidant defense system in plants. Plants have several mechanisms to defend themselves against arsenic-induced stress. Compartmentation and translocation of arsenic are reported to be basic mechanisms involved in plant arsenic-tolerance (Sri et al., 2009). When these mechanisms become insufficient, biochemical processes can become involved in arsenic 
detoxification. Three mechanisms might be employed in this respect: i) a tolerant plant might use to survive or even grow in stress situation; ii) the tolerant plant may minimize the production of ROS; iii) it may protect itself from the deleterious degradative reactions associated with ROS by efficiently scavenging ROS; or it might repair the injury after the degradation has been observed.

Although the mechanism of enhancing PPO activity in species of Basella alba is not clarified well, the current study reveals that the increased PPO activity might be due to the optimum cellular concentration of calcium since administration of calcium channel blocker prevents the PPO activity induced by high temperature. The entry of calcium through calcium channel triggers the intracellular mechanism of enhancing the cellular metabolic functions as $\mathrm{Ca}^{2+}$ is recognized to be a second messenger. Therefore, inhibition of entry of calcium ion by blocker might be involved in prevention of PPO activity in this species of plant. Recent reports have identified and characterized a class of hyperpolarization-activated $\mathrm{Ca}^{2+}$-permeable cation channels in several types of plant cells, including tomato (Lycopersicon esculentum) suspension culture cells (Gelli et al., 1997), guard cells (Hamilton et al., 2000) and root elongation zone epidermal cells (Demidchik et al., 2003). In tomato suspension culture cells, fungal elicitor activation of ICa-type $\mathrm{Ca}^{2+}$ channels is inhibited by the antioxidant, dithiothreitol (Gelli et al., 1997), indicating a possible role for ROS in channel activation. Elicitors evoke both cytosolic $\mathrm{Ca}^{2+}$ increases and ROS generation; however, the peptide elicitor harpin induces only ROS generation. In some cases, $\mathrm{Ca}^{2+}$ elevations have been reported upstream of ROS production; in other cases, $\mathrm{Ca}^{2+}$ elevations occur downstream of ROS production (Bowler and Fluhr, 2000), indicating complex spatiotemporal $\mathrm{Ca}^{2+}$ elevation mechanisms. In Arabidopsis root hairs, enhancement of cytosolic $\mathrm{Ca}^{2+}$ was caused by oxidative stress (Coelho et al., 2002). A recent study showed that the allelopathic toxin- catechin causes rapid ROS production, followed by ROSinduced $\mathrm{Ca}^{2+}$ increases in Centaurea diffusa and Arabidopsis roots, suggesting a broader role for ROS-Ca ${ }^{2+}$ signaling in pathogenic responses (Bais et al., 2003).

Metabolic adjustments in response to unfavorable conditions are dynamic and not only depend on the type and strength of the stress, but also on the cultivar and the plant species. Some metabolic changes are common to salt, drought, and temperature stress, whereas others are specific.
Enzymatic browning is a significant problem in a number of fruits and vegetables such as strawberry, grape, potato and lettuce (Chisari et al., 2007; Gawlik-Dziki et al., 2007). The discoloration in fruits and vegetables by enzymatic browning, resulting from conversion of phenolic compounds to o-quinones which subsequently polymerize to be a brown or dark pigment and the enzymes involved these processes are PPO and POD (Jiang et al., 2004). Recent study reveals that high temperature acclimation adversely affects physiological and morphological structures of plants (Almeselmani et al., 2006) and the nutritional deficiency has been observed in response to high temperature. Therefore, it is reasonable that adverse oxidative effects caused by high temperature acclimation might be correlated to the alteration of physiology of leaf of $B$. alba and also to the nutritional deficiencies particularly the uptake of essential nutrients from the soil and also from the environment. Further studies are needed to clarify the mechanisms linked to the above approaches. Measurement of PPO in leaf of B. alba might be an essential approach and will give a new insight to clarify the mechanism of diverse metabolic functions of plant as well as help in analysis of physiology of $B$. alba. Moreover, regulation of this enzyme is not only mediated by hot environment but also might be by other chemical mediators like arsenic and calcium in the environment.

\section{Conclusion}

The results show that high temperature induces metabolic alterations regarding the enhancement of polyphenol oxidase in leaf therefore, assumes to be involved in the alteration of physiology of plants $B$. alba. The adverse environment caused by high temperature produced the severe effect on the plants and thereby plants face the stress to physiological and molecular level and therefore, different regulatory metabolic alterations were observed in the circumstances. High temperature induced oxidative stress and injury is frequently observed in the critical environment and to overcome these effects, some enzymes are over expressed where PPO might be involved which is an essential parameter for characterization for the prevention of the anti-oxidative effects in this species of vegetables. The additive effects on polyphenol oxidase activity in this species is because of the effects of arsenic as arsenic has been found to be involved in inducing oxidative stress and cause the generation of reactive oxygen species. The findings may enhance the clarification of the accumulation of arsenic and its prevention 
and detoxification process. The enhanced PPO activity in leaf of this species could be mediated through calcium channel which might be regulatory mechanism by which the plants survive in the adverse environment. Species adapted by natural selection to hot environments have evolved a number of physiological and morphological means to improve survival in the face of extended hot periods. Plants possess nutritional or energy deficiency during the temperature stress causing higher oxidative effects and the enzyme might be involved in metabolic regulation particularly the prevention of cellular damage and injury of the plants.

\section{Acknowledgement}

This study was carried out in the Department of Biochemistry and Molecular Biology, Rajshahi University and supported by the University Grant Commission (UGC), Bangladesh.

\section{Author contributions}

M. S. H. contributed to all aspects of this manuscript. M. R. S. and M. A. R. were involved in the respective research work. M. A. Z. and M. M. I. were also associated in the respective works particularly their valuable suggestions and inspirations. J. M. A. helped in editing and preparation of the final manuscript.

\section{References}

Almeselmani, M., P. S. Deshmukh, R. K. Sairam, S. R. Kushwaha and T. P. Singh. 2006. Protective role of antioxidant enzymes under high temperature stress. Plant Sci. 171:382388.

Apel, K. and H. Hirt. 2004. Reactive oxygen species: metabolism, oxidative stress and signal transduction. Ann. Rev. Plant Biol. 55:373-399.

Babu, N. R. and V. R. Devraj. 2008. High temperature and salt stress response in French bean (Phaseolus vulgaris). Aust. J. Crop Sci. 2:40-48

Bais, H. P., R. Vepachedu, S. Gilroy, R. M. Callaway and J. M. Vivanco. 2003. Allelopathy and exotic plant invasion: from molecules and genes to species interactions. Science 301:1377-1380.

Bowler, C. and R Fluhr. 2000. The role of calcium and activated oxygens as signals for controlling cross-tolerance. Trends Plant Sci. 5:241-246.
Boullier, A., D. A. Bird, M. K. Chang, E. A. Dennis, P. Friedman, K. Gillotre-Taylor, S. Horrko, W. Palinski, O. Quehenberger, P. Shaw, D. Steinberg, V. Terpstra and J. L. Witztum. 2001. Scavenger receptors, oxidized LDL, and atherosclerosis. Ann. N. Y. Acad. Sci. 947:214-222.

Chisari, M., R. N. Barbagallo and G. Spagna. 2007. Characterization of polyphenol oxidase and peroxidase and influence on browning of cold stored strawberry fruit. J. Agric. Food. Chem. 55(9):3469-3476.

Coelho, A. R Taylor., K. P. Ryan, I. Sousa-Pinto., M. T. Brown, C. Brownlee. 2002. Spatiotemporal patterning of reactive oxygen production and $\mathrm{Ca}^{2+}$ wave propagation in Fucus rhizoid cells. Plant Cell 14:2369-2381.

Demidchik, V., S. N. Shabala, K. B. Coutts, M. A. Tester and J. M. Davies. 2003. Free oxygen radicals regulate plasma membrane $\mathrm{Ca}^{2+}$ - and $\mathrm{K}+$-permeable channels in plant root cells. J. Cell Sci. 116:81-88.

Gelli, A., V. J. Higgins and E. Blumwald. 1997. Activation of plant plasma membrane $\mathrm{Ca} 2+-$ permeable channels by race-specific fungal elicitors. Plant Physiol. 113:269-279.

Gawlik-Dziki, U., U. Zlotek and M. Swieca. 2008. Characterization of polyphenol oxidase from butter lettuce (Lactuca sativa var. capitata L.). Food Chem. 107(1):129-135.

Hamilton, D. A., A. Hills, B. Köhler and M. R. Blatt. 2000. $\mathrm{Ca}^{2+}$ channels at the plasma membrane of stomatal guard cells are activated by hyperpolarization and abscisic acid. Proc. Natl. Acad. Sci. USA. 97:49674972.

Jiang, Y. M., X. W. Duan, D. Joyce, Z. Q. Zang and J. R. Li. 2004. Advances in understanding of enzymatic browning in harvested litchi fruit. Food Chem. 88(3):443-446.

Janska, A., P. Marsik, S. Zelenkova and J. Ovesna. 2010. Cold stress and acclimation- what is important for metabolic adjustment? Plant Biol. 12(3):395-405.

Larkindale, J. and M. R. Knight. 2002. Protection against heat stress-induced oxidative damage in Arabidopsis involves calcium, abscisic acid, ethylene, and salicylic acid. Plant Physiol. 128:682-695.

Lee, D. H. and C. B. Lee. 2000. Chilling stress- 
induced changes of antioxidant enzymes in the leaves of cucumber: In gel enzyme activity assays. Plant Sci. 159(1):75-85.

Mayer, A. M. 2006. Polyphenol oxidases in plants and fungi: Going places? A review. Phytochemistry 67:2318-2331.

Mascher R., B. Lippmann, S. Holzinger and H. Bergmann. 2002. Arsenic toxicity effects on oxidative stress response molecules and enzymes in red clover plants. Plant Sci. 163:961-969.

Mahadevan, A. and R. Sridhar. 1982. Methods in Physiological Plant Pathology. 2nd ed. Sivakami Publications, Madras, India, pp. 316.

Mahajan, S. and N. Tuteja. 2005. Cold, salinity and drought stresses: An overview. Arch. Biochem. Biophys. 444:139-158.

Makoi, J. H. J. R. and P. A. Ndakidemi. 2007. Biological, ecological and agronomic significance of plant phenolic compounds in rhizosphere of the symbiotic legumes. Afr. J. Biotechnol. 6(12):1358-1368.

Mumthas, S., A. A. Chidambaram, P. Sundaramoorthy and K. Sankar Ganesh. 2010. Effect of arsenic and manganese on root growth and cell division in root tip cells of green gram (Vigna radiata L.). Emir. J. Food Agric. 22(4):285-297.

Oidaira, H., S. Satoshi, K. Tomokazu and U. Takashi. 2000. Enhancement of antioxidant enzyme activities in chilled rice seedlings. Plant Physiol. 156:811-813.

Premalatha, B. and G. Rajgopal. 2005. Cancer- an ayurvedic perspective. Pharmacol. Res. 51:1930.

Queiroz, C., M. L. M. Lopes, E. Fialho and V. L. Valente-Mesquita. 2008. Polyphenol oxidase: Characteristics and mechanisms of browning control. Food Rev. Int. 24(4):361-375.

Roshan, A., K. H. N. Naveen and S. D. Shruthi.
2012. A review on medicinal importance of Basella alba L. Int. J. Pharma. Sci. Drug Res. 4(2):110-114.

Scandalios, J. G. 2005. Oxidative stress: molecular perception and transduction of signals triggering antioxidant gene defenses. Braz. J. Med. Biol. Res. 38(7):995-1014.

Srivalli, B., C. Vishanathan and K. C. Renu. 2003. Antioxidant defense in response to abiotic stresses in plants. J. Plant Biol. 30:121-139.

Sri, M., S. Kumar, D. Chakrabarty, P. K. Trivedi, S. Malick, P. Mishra, D. Shukla, S. Mishra, S. Srivastava, R. D. Tripathi and R. Tuli. 2009. Effect of arsenic on growth, oxidative stress, and antioxidant system in rice seedling. Ecotoxicol. Environ. Saf. 72:1102-1110.

Scotti-Campos, P., J. N. Semedo, I. Pais, M. Oliveira, J. Passarinho and J. C. Ramalho. 2014. Heat tolerance of Portuguese old bread wheat varieties. Emir. J. Food Agric. 26(2):170-179.

Singh, N., L. Q. Ma, M. Srivastava and B. Rathinasabapathi. 2006. Metrabolic adaptations to arsenic-induced oxidative stress in Pteris vittata L. and Pteris ensiformis L. Plant Sci. 170:274-282,

Velero, E., R. Varon and F. Garcia-Carmona. 2003. Catalytic oxidation of acetaminophen by tyrosinase in the presence of L-proline: a kinetic study. Arch. Biochem. Biophys. 16:218-226.

Yadegari, L. Z., R. Heidari and J. Carapetian. 2007. The influence of cold acclimation on proline, malondialdehyde (MDA), total protein and pigments contents in soybean (Glycine max) seedlings. J. Biol. Sci. 7(8):1436-1441.

Zlatev, Z. and F. C. Lidon. 2012. An overview on drought induced changes in plant growth, water relations and photosynthesis. Emir. J. Food Agric. 24(1):57-72. 